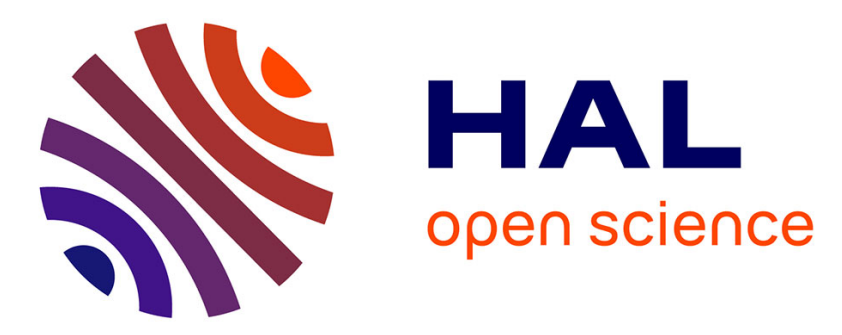

\title{
Decomposing Packaged Services Towards Configurable Smart Manufacturing Systems
}

Taehun Kim, Seunghwan Bang, Kiwook Jung, Hyunbo Cho

\section{To cite this version:}

Taehun Kim, Seunghwan Bang, Kiwook Jung, Hyunbo Cho. Decomposing Packaged Services Towards Configurable Smart Manufacturing Systems. IFIP International Conference on Advances in Production Management Systems (APMS), Sep 2015, Tokyo, Japan. pp.74-81, 10.1007/978-3-31922759-7_9. hal-01431158

\section{HAL Id: hal-01431158 \\ https://hal.inria.fr/hal-01431158}

Submitted on 10 Jan 2017

HAL is a multi-disciplinary open access archive for the deposit and dissemination of scientific research documents, whether they are published or not. The documents may come from teaching and research institutions in France or abroad, or from public or private research centers.
L'archive ouverte pluridisciplinaire HAL, est destinée au dépôt et à la diffusion de documents scientifiques de niveau recherche, publiés ou non, émanant des établissements d'enseignement et de recherche français ou étrangers, des laboratoires publics ou privés.

\section{(c)(1)}

Distributed under a Creative Commons Attribution| 4.0 International License 


\title{
Decomposing packaged services towards configurable smart manufacturing systems
}

\author{
Taehun Kim, Seunghwan Bang, Kiwook Jung and Hyunbo Cho \\ Pohang University of Science and Technology \\ 77 Cheongam-Ro, Nam-Gu, Pohang, Gyeongbuk, Korea 790-784 \\ \{taehun_kim, seunghwanb, kiwook, hcho\}@postech.ac.kr
}

\begin{abstract}
Smart Manufacturing Systems have the ability to adapt to rapidly changing requirements. Software components of the manufacturing systemservices under Service Oriented Architecture - must be configured dynamically to meet such requirements. Currently, software vendors provide packaged services, so they are not easily reconfigurable. Thus, engineers or production managers face difficulty in composing services with the appropriate functionality and quality. The objective of this paper is to discuss high-level requirements for such a unit service concept and provide an initial use case to illustrate how the unit service concept may apply new technologies to improve service. We propose a decomposition of target service according to standard model, and we claim the limitations of decomposed unit services, and new technologies and opportunities for each decomposed services.
\end{abstract}

Keywords: manufacturing service; smart manufacturing; production planning

\section{Introduction}

Smart Manufacturing Systems (SMSs) are defined by advent of new technologies that promote rapid and widespread information flow within the systems and surrounding its control [1]. New technologies, such as internet of things (IoT), big data analytics, and predictive analytics, enable collecting and processing of huge amounts of data, rapid and precise physical systems monitoring, and deeper and advanced analysis for those data. New technologies offer chances to develop new manufacturing services, or to improve previous services.

However, previous manufacturing supporting systems, such as enterprise resource planning, material requirements planning, and production planning, have limited availability to apply these technologies. Systems to support manufacturing for enterprises have variety scopes and level of details, but, the lack of a standard industry approach to production management results in customized software or use of a manual approach [2]. The resulting systems have specified structure, low level of modularity and low level of interoperability. In the worst case, the existing system must be reconstructed before it applies new technologies for SM. 
A configurable SMS is a manufacturing support system that dynamically composes unit level manufacturing services to satisfy manufacturing requirements. To be configurable, a whole packaged service should be decomposed into unit level services and be interoperable. Configurable SMS enables service oriented architecture based manufacturing support systems, and these systems can be operated with lower cost and easier management than existing systems, and can provide the most appropriate services to satisfy manufacturing requirements.

To prepare the era of SM, manufacturing services required should be collected and generalized. Thus, in this paper, we tried to start by analyzing one instance. We selected one production planning service as our target service to be analyzed, and discussed its decomposition and applicability of new technologies for SM. Section 2 describes target service details and its decomposition into unit services according to the standard model. Section 3 identifies the limitation of these services and opportunities to improve these services in the era of SM. Section 4 concludes the paper and discusses future work.

\section{Target service description}

\subsection{Target service details}

The target service is Production Planning and Management. This service is performed by three modules: (1) order-processing, (2) production-planning, and (3) productionmanagement. Each module interoperates through a specified interface. The orderprocessing module is involved in defining the relative importance of order, and selection of orders that will be serviced. The production plan will be based on the customer orders selected during order processing. The production-planning module generates a production plan considers manufacturing capability. The productionmanagement module tracks production and detects abnormal conditions. After detecting an abnormal condition, if the uncommitted production plan (future plan) is affected critically, then the production planning module modifies plan to consider the effect of abnormal condition.

This service covers production planning and revising of the plan when an abnormal situation happens. Specifically, the scope of this service is classified into level 3 and level 4 according to the functional hierarchy model [3]. Production-planning module performs level 4 activities, and the production-management module performs level 3 activities. This functional hierarchy model does not consider order processing (Fig. 1).

In the functional data flow model [3], the target service's scope covers orderprocessing, production scheduling, and production control functions. The order processing function is enabled by the order-processing module, and productionschedule function is enabled by production-planning module, and production control function is enabled by production-management module (Fig. 2). 


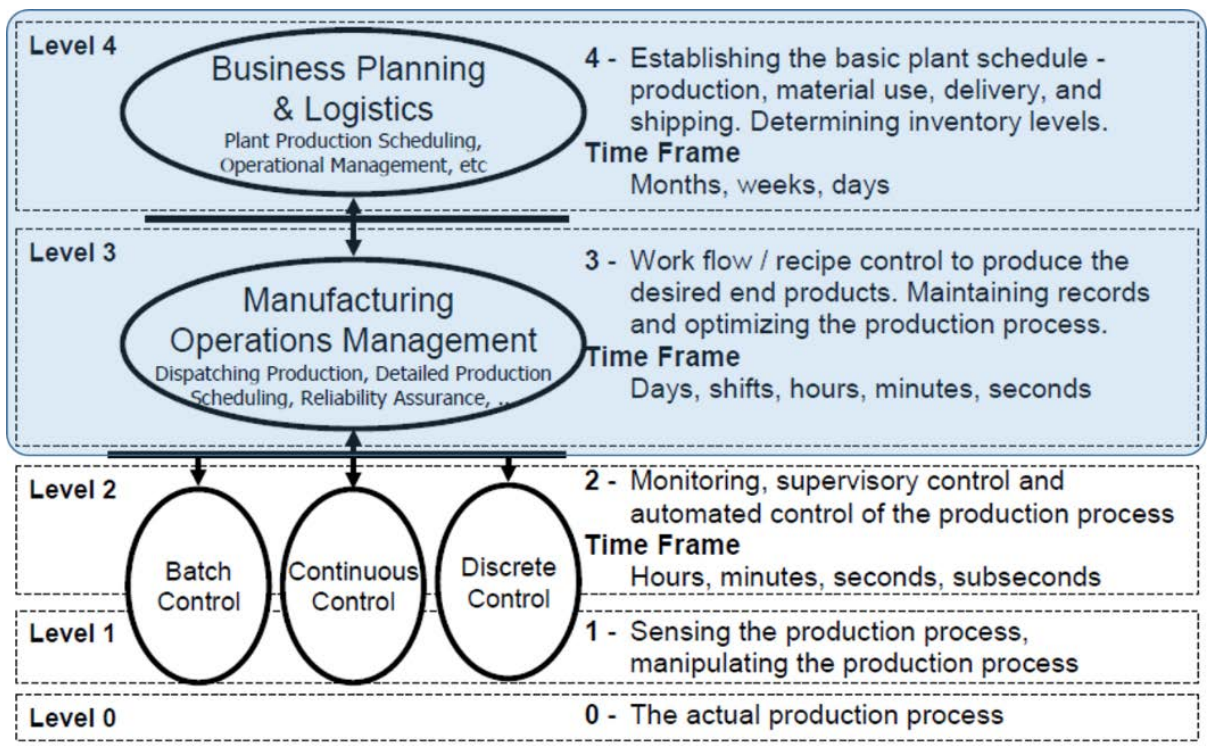

Fig. 1. Scope of target service in the functional hierarchy model

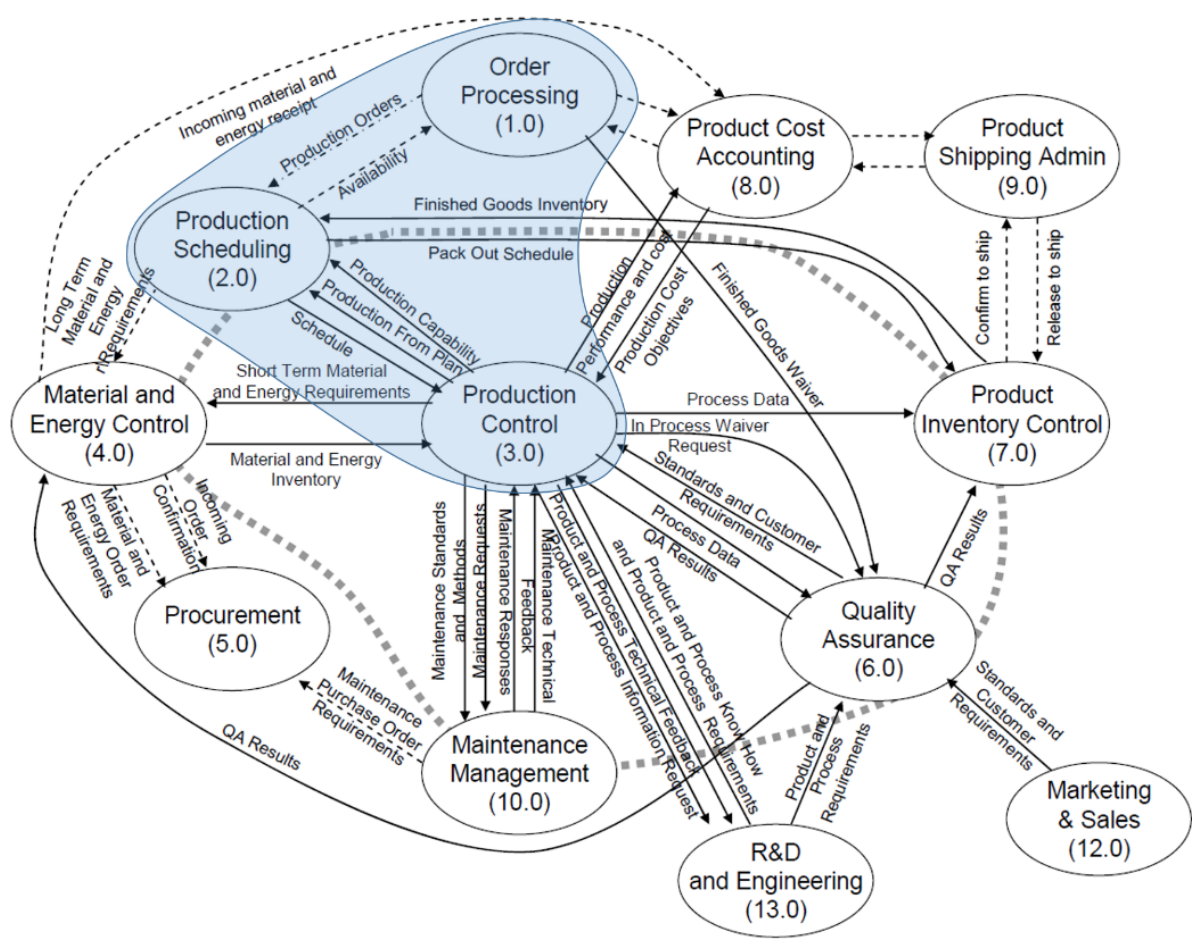

Fig. 2. Scope of target service in the functional data flow model 


\subsection{Target service decomposition}

We decomposed our target service into functions according to the functional data flow model, these functions are order processing, production schedule, and production control. Each corresponds to a module of the target service. Each function is decomposed into sub-functions, which are acting as unit services in service-oriented architecture. Detailed description of sub-functions are as follows (Fig. 3).

- Order processing includes order prioritization, order selection, and order consolidation.

- Order prioritization determines the relative importance of production orders, and uses it when partitioning an order if production cannot be performed. It generates the production order list with each order's priority.

- Order selection determines which order to be produced in this scheduled period and generates the production order list for production schedule. Order selection should consider many attributes such as due date, production and transportation lead time, order priority, and minimum order quantity.

- Order consolidation merges orders that have the same attributes such as product model group, due date, and special production requirements. This step reduces the number of variables used in the production schedule.

- By these functions, the initial orders become production orders which are the input of the production schedule function.

- Production schedule includes product definition reference, capability reference, production request generation, schedule modification, and availability offer.

- Product definition reference includes shared information between product production rule, bill of material, and bill of resources [3]. The information is related to how to produce this product. The information includes the parts and the numbers of them required to be assembled into this product, the operations required, and other customer-specific requirements. This information ensure production of exactly the required product.

- Capability reference includes the production resources information including personal resources capability, equipment capability, and material capability. We use this information to prevent our schedule from exceeding the production capability.

- Production request generation outputs requests for production. After the scheduling, the result of production schedule should be shared to ensure efficient production. The production request includes when and how many items should be produced or assembled, how many materials to be used, and where the items should be delivered. These production requests are generated according to production schedule.

- Schedule modification adjusts the given schedule according to order and production environmental changes. We should modify our schedule if these changes happen frequently.

- Availability offer provides availability information on whether components are available. After the scheduling, some orders are fulfilled whereas others are not. 
Information about availability is conveyed to the customer and the order is mediated.

- By these functions, requests for production operation and availabilities for the production orders are generated.

- Production control includes production response generation, identification of event and alarm information, and production capability management.

- Production response generation outputs the production result data from the requests. Production response includes requested production quantity, actual production quantity, produced site, area and facility information, worker information, and start and end time of production operation. This process is required, to track the production requests and to compare the difference between the plan and real production.

- Identification of event and alarm information identifies special problems that can affect to production; i.e., facility breakdown, drop of quality or yield, material shortage and other abnormal signs.

- Production capability management manages personal, facility, material and energy capability during production. This component manages the records of committed capability usage and updates the history according to the production. This component also manages available capability information.

- By these functions, the production responses are fed back to production schedule function to modify the schedule, and the capability is updated according to the real situation.

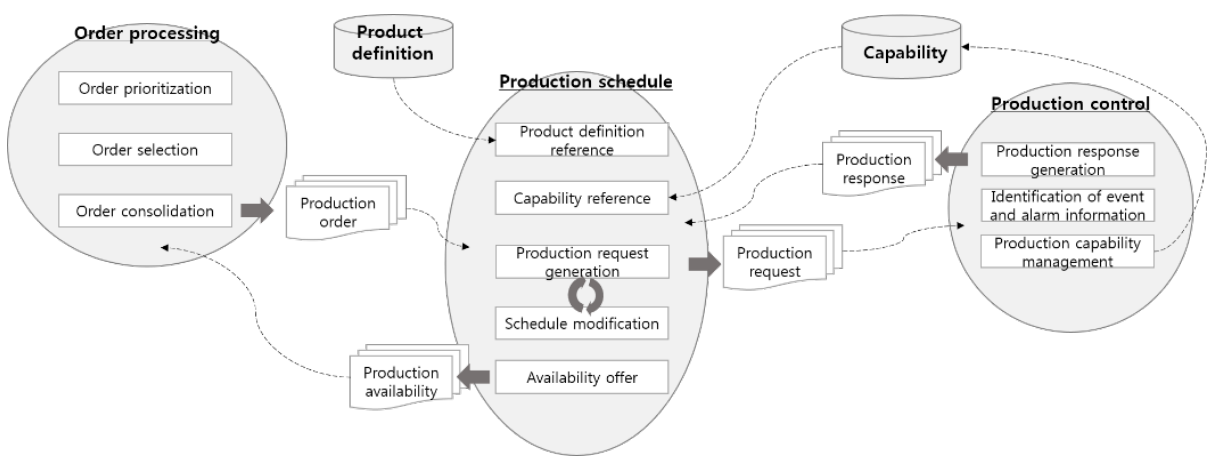

Fig. 3. Target service decomposition into unit level services

\section{$3 \quad$ Limitations and opportunities}

\subsection{Limitation of target service}

The services had limitation when the provided functions depended on the users' decision. Users may fail to make consistent and optimized decisions when they use the 
production-planning service because of its high complexity [4]. In addition, because sensor and data gathering techniques are advancing, they should make decisions increases at some real-time decision-making points.

Order prioritization is critical to determine which order is produced or not. Improper priority can cause loss of critical customers' business because the priority of their order has been reduced and the schedule is prone to ignore lower-priority orders. However, order prioritization is done manually in many enterprises. Some simple rules were used: the highest priority is given to for the most frequent and most important customers, and the lowest priority is given to for small orders. Manual determination of order priorities causes operational problems, which result from inconsistent prioritization policy, and leads to inappropriate optimization.

For another example, schedule modification was dependent on the planners' decision. After the order or production environmental changes were reported, planners make decisions about the production, including cancellation of committed production request, re-allocation of facilities and materials, and determination of re-scheduling period. These decisions take time, but the planner cannot keep up with all change in order or production environment.

\subsection{Opportunity discovery}

New technologies and methods can be introduced to develop new services, or to improve services. Computational components and physical components of manufacturing enterprises are becoming increasingly seamlessly and closely integrated to perceive changes in the real system [2]. Current efforts in the cyber-physical systemsbased approach will produce many new value-creation opportunities for future manufacturing [5]. We will describe the opportunities application to our target service (Fig. 4).

At first, big data and predictive analytics can be used to innovate the services. For example, from the big data and predictive analytics, the past order prioritization and selection history are analyzed and patterns can be recognized. Pattern-recognitionbased order prioritization and selection can support consistent and optimized decisionmaking.

IoT and real-time information can be used to innovate manufacturing services. For example, real-time information gathering and processing enable real-time identification of event and alarm information from various sensors attached to the facilities. According to this real-time information, real-time production responses and dynamic schedule modification are possible [6, 7, and 8].

In addition, predictive analytics enables predictive maintenance, which in turn enables predictive maintenance-based production planning. Many approaches use fixed or periodic (deterministic) maintenance schedules; this time-based and hands-on equipment maintenance is still the norm in industrial processes, but this practice may be inefficient [9]. Production plan to exclude these unnecessary maintenance events increase their effectiveness. 


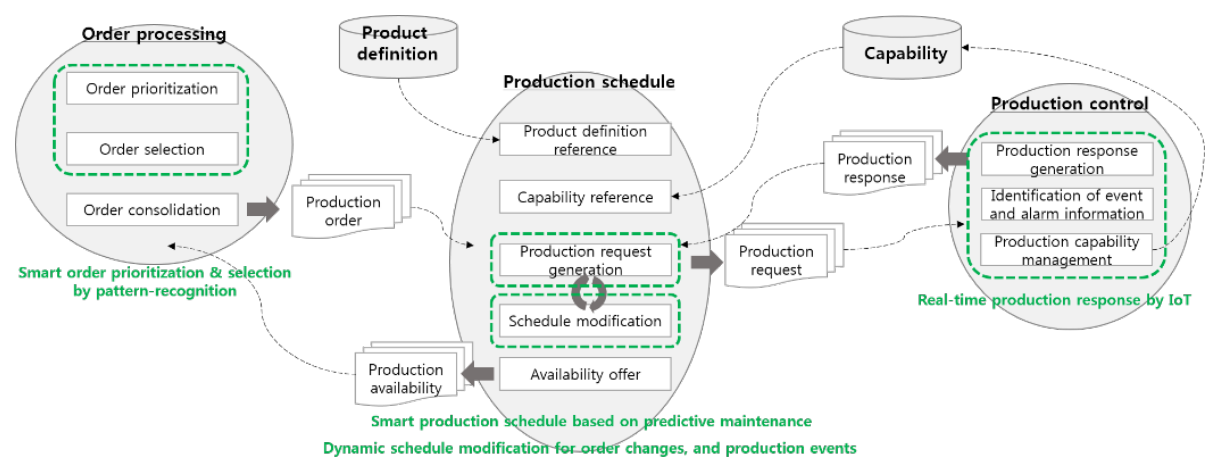

Fig. 4. Target service decomposition and new technologies enabling opportunities

\section{Conclusion \& future work}

This paper described a target service, and decomposed function into unit services. Our target service consists of order processing, production schedule, and production control functions, and each has several sub-functions (unit services). Several methods and new technologies, such as IoT, big data analysis, cyber physical system, and predictive analytics, can be used to innovate current unit services and whole function.

Towards SM, we plan to collect more instances, and we will generalize the set of manufacturing services from these instances. These services will be analyzed, and new and advanced services from their improving opportunities and relationships will be discovered. The services will be decomposed into unit level services to enable the dynamic composition of manufacturing services for specific requirements.

\section{Acknowledgement}

This work was partly supported by the ICT R\&D program of MSIP/IITP [B010115-0650, Development of Smart Manufacturing Operation Platform for Hightech Industry].

\section{Reference}

1. Jung, K., Morris, K. C., Lyons, K. W., Leong, S., \& Cho, H. (2015). Mapping Strategic Goals and Operational Performance Metrics for Smart Manufacturing Systems. Procedia Computer Science, 44, 184-193. doi:10.1016/j.procs.2015.03.051

2. National Institute of Standards and Technology. Workshop report on foundations for innovation in cyber-physical systems. Jan 2013. http://www.nist.gov/el/upload/CPSWorkshopReport-1-30-13-Final.pdf 
3. ANSI/ISA-95. (2010), ANSI/ISA-95.00.01-2010, Enterprise-Control System Integration, Part 1: models and terminology.

4. Lanza, G., Stricker, N., \& Peters, S. (2013). Ad-hoc Rescheduling and Innovative Business Models for Shock- robust Production Systems. Procedia CIRP, 7, 121-126. doi:10.1016/j.procir.2013.05.021

5. Lee, J., Lapira, E., Bagheri, B., \& Kao, H. an. (2013). Recent advances and trends in predictive manufacturing systems in big data environment. Manufacturing Letters, 1(1), 3841. doi:10.1016/j.mfglet.2013.09.005

6. Cowling, P., \& Johansson, M. (2002). Using real time information for effective dynamic scheduling. European Journal of Operational Research, 139(2), 230-244. doi:10.1016/S0377-2217(01)00355-1

7. Dong, Y.-H., \& Jang, J. (2012). Production rescheduling for machine breakdown at a job shop. International Journal of Production Research, 50(10), 2681-2691. doi:10.1080/00207543.2011.579637

8. Katragjini, K., Vallada, E., \& Ruiz, R. (2012). Flow shop rescheduling under different types of disruption. International Journal of Production Research, (April 2015), 1-18. doi:10.1080/00207543.2012.666856

9. Hashemian, H. M., \& Bean, W. C. (2011). State-of-the-art predictive maintenance techniques. IEEE Transactions on Instrumentation and Measurement, 60(10), 3480-3492. doi:10.1109/TIM.2009.2036347 